\title{
Wer bin ich?
}

\section{Erhard Taverna}

Dr. med., Mitglied der Redaktion

James Ensors Maskenbilder und Skelette, Henrik Ibsens Vorstellung der Lebenslüge. Die vielen Entwicklungsromane vom Wilhelm Meister bis zum grünen Heinrich und danach. Max Frischs Gantenbein und das Scheitern des Verhaltensforschers Kürmann im Theaterspiel Biografie. Malerei und Literatur leben von der existentiellen Kernfrage: «Wer bin ich, wer sind wir?»

Dieser kompliziertesten Frage der Welt stellt sich die Ausstellung des Vögele-Kulturzentrums ${ }^{1}$ in Pfäffikon, Kanton Schwyz. Was kann ich wissen, was soll ich tun, was darf ich hoffen? Eine Entdeckungsreise führt durch die verschiedenen Facetten unserer Identität. «Wir durchschreiten das Leben mit einer Art Arbeitshypothese des eigenen Selbst» bemerken die Kuratoren zu den szenographischen Stationen auf dem langen Weg der individuellen Persönlichkeitsentwicklung. Zum Thema Herkunft und Familie posieren Erwachsene in der gleichen Kleidung und vor identischem Hintergrund, wie auf ihrem Kinderfoto. Videoinstallationen stellen eineiige Zwillinge direkt nebeneinander, die in einem Interview die gleichen Fragen beantworten. Der raffinierte Zusammenschnitt macht in den subjektiven Antworten deutlich, wie trotz genetischer Übereinstimmung eigene Perspektiven das Leben mitbestimmen. Gemeinsam Werte wie Traditionen, Sprache und Religion prägen das kulturelle Milieu. Ein besonders anschauliches Beispiel für die kritische Präsentation emotional aufgeladener Objekte zur Nationalität sind die rot-weissen Fadenbündel auf drei Regalbrettern. Der Künstler hat achtzehn Nationalflaggen, die aus den Farben rot und weiss bestehen, auf Polyesterknäuel reduziert. Aufgelegte Postkarten mit Fragen erinnern an die Volksbefragungen «Point de Suisse ${ }^{2}$ von 2014. Welches Ereignis aus der Schweizergeschichte möchten sie streichen, worin ist das Land ein Vorbild für andere Nationen? Ein crossmediales Kunstprojekt zur Vermessung der Schweiz, eine detaillierte und spannende Online-Umfrage zur Befindlichkeit der Nation. Zum Thema Körper zeigt eine Fotoserie, wie Chemotherapie Menschen verändert. Mit einem ganz anderen Aspekt verblüfft der Fotograf Philippe Halsmann, der in den frühen fünziger Jahren die porträtierten Persönlichkeiten aufforderte, vor der Kamera in die Höhe zu springen. «Wenn sie eine Person auffordern, in die Luft zu springen, kristallisiert sich ihre Aufmerksamkeit auf den Akt des Springens und die Maske fällt, so dass die echte Persönlichkeit zum Vor-

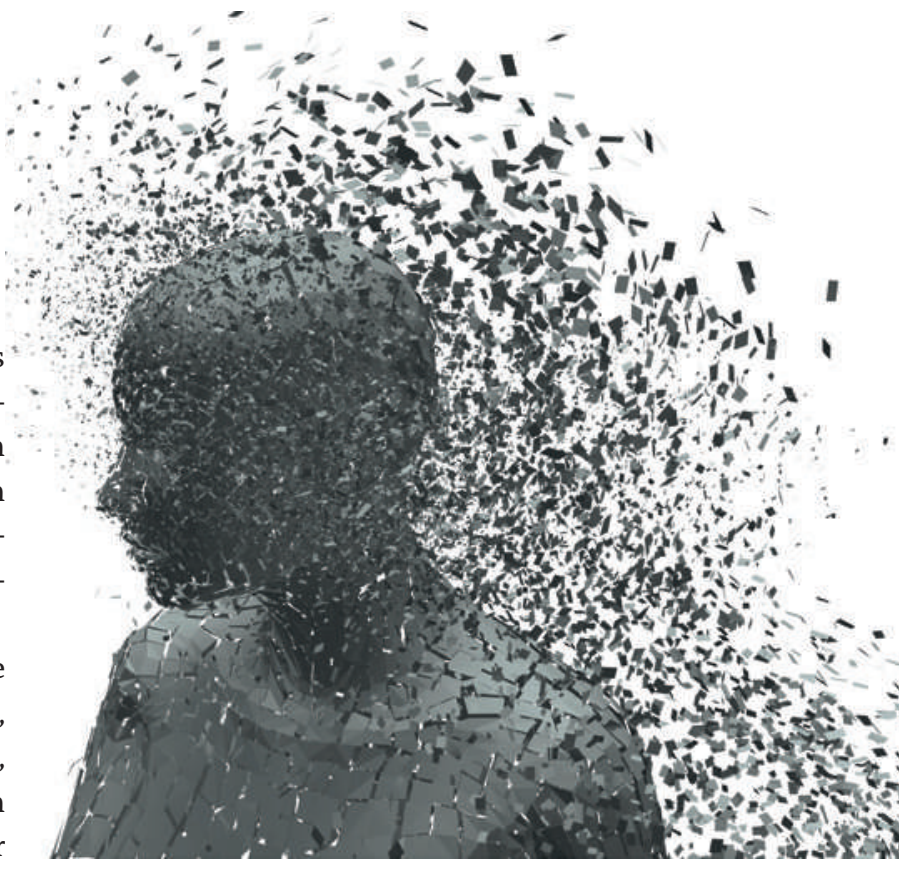

Was kann ich wissen, was soll ich tun, was darf ich hoffen? Die Ausstellung des Vögele-Kulturzentrums im schwyzerischen Pfäffikon stellt sich den existentiellen Fragen des Menschseins auf ganz unterschiedliche, künstlerische Arten (Symbolbild, Abbildung zeigt kein Werk der Ausstellung).

schein kommt.» Seinen Jumps folgten Menschen wie Grace Kelly, der Hund Duke und die Duchess of Windsor, Marilyn Monroe, Salvador Dalí und viele andere. Status und Psyche sind weitere Stationen einer einfallsreichen Reise zu den Theorien moderner Psychologen, die jedem Menschen multiple Persönlichkeiten zuschreiben. Wer will, kann im Roten Buch von Carl Gustav Jung blättern, Erkenntnisse aus der Neurobiologie studieren oder Kurzfilme von Alain de Botton und ein Gedankenexperiment von Plutarch, das Schiff des Theseus, in Comicform betrachten. Schülerarbeiten und Workshop-Beiträge erinnern daran, dass die Kunstvermittlung und die Zusammenarbeit mit Schulen ein besonderes Anliegen des Kulturzentrums sind. Ein grüner Pass zur Eintrittskarte stellt als Hausaufgabe Fragen vom Beginn des Lebens bis zur letzten Seite: «Das Ich ist niemals fertig.» Herausgegriffen sind hier stellvertretend einige Beispiele aus zahlreichen weiteren Darstellungen, bei denen jeder Besucher und jede Besucherin anderes entdecken und damit eigene Akzente setzen wird.

Das 100. «Vögele Kultur Bulletin» vertieft die Ausstellungseindrücke mit informativen Beiträgen bekannter Autoren und Autorinnen. Mehrere Kino-Sonntage zeigen Filme. Führungen, ein Expertengespräch und ein Künstlergespräch mit Manon, vertiefen die Besuchseindrücke.

Bildnachweis

(c) Agawa288 | Dreamstime.com 